\title{
Using military resources to fight disease
}

I $\mathrm{n}$ a sign that international concern about infectious diseases is attracting attention in military circles, the United States government has launched the Global Health Security Agenda (GHSA), a multinational effort to confront antibiotic resistance, epidemics,

To kickstart the effort, the government earmarked US\$40 million from the budgets of the Department of Defense (DOD) and the US Centers for Disease Control and Prevention (CDC), with another US\$45 million requested in this year's budget. "We're bringing DOD resources to the Global Health Security Agenda by leveraging the department's long history of medical and health innovation," Andrew C. Weber, assistant secretary of defense for nuclear, chemical and biological defense programs, explained at the Feb. 13 launch.

The aim is to create a worldwide "interconnected network of emergency operations centres to help manage these outbreaks," according to Laura Holgate, senior director of weapons of mass destruction terrorism and threat reduction at the National Security Council in Washington, DC. Pooling funds from defence and health programs will extend the agenda's reach, Holgate said in video-recorded comments.

"When you look at how we're organized across our government on our various health and security strategies, you can see some common threads among them," she said. "We all face the same threats." bioterrorism and disease outbreaks.

The mixture of global health and security funding may prove problematic, however, says Ron Labonte, Canada Research Chair in Globalization and Health Equity at the University of Ottawa in Ontario. "It raises the question whether this is a defence or health agenda, and it is worrying that infectious diseases are being defined as a kind of terrorist threat."

With the growth of antimicrobial resistance substantially rooted in pharmaceutical industry practices and international trade agreements, he argues, bolstered security measures may amount to "a kind of proximate prevention, rather than structural change."

Support from the DOD for the GHSA indicates the Pentagon sees improving global health as a potential new mission, says J. Stephen Morrison, director of the Global Health Policy Center at the Center for Strategic and International Studies in Washington, DC. Between 2002 and 2005, DOD's share of US official development assistance increased from $5.6 \%$ to $21.7 \%$, Morrison noted in a 2008 report.

"There has been a shift within DOD thinking," says Morrison. "There's a broadening awareness of the legitimacy of a global health security agenda."

Morrison acknowledges that military involvement inevitably creates tension. "This debate has been underway for some time. The civilian agencies don't want to see their roles usurped."

Military encroachment into public

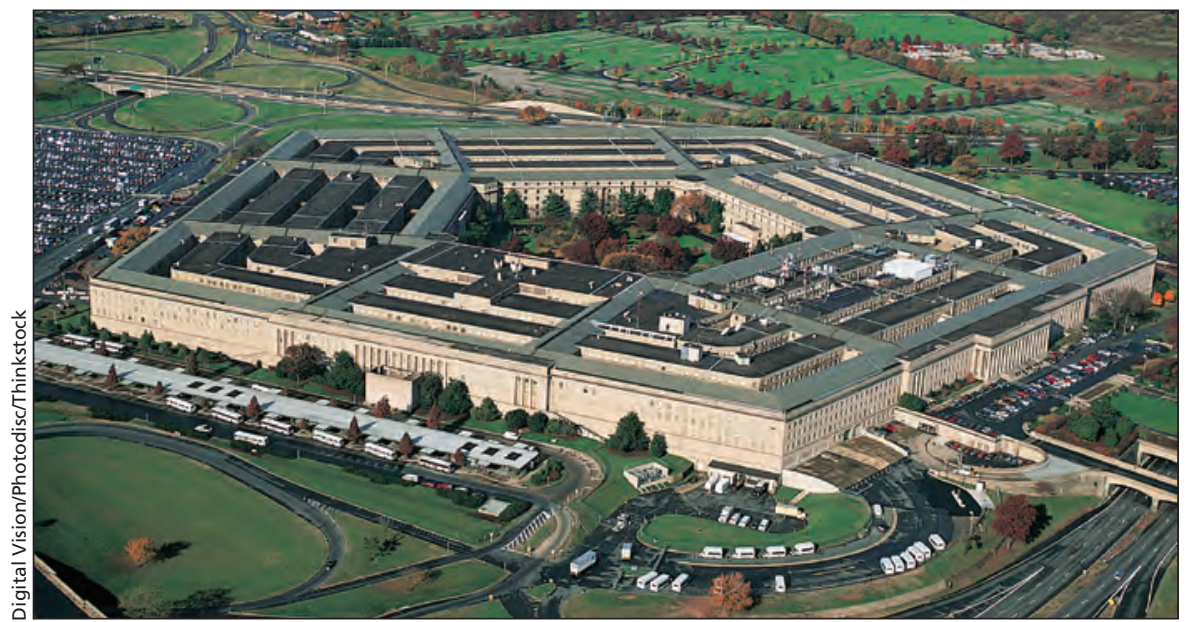

Support from the US Department of Defense for a new health agenda may indicate that the Pentagon sees improving global health as a potential new mission. health matters can be highly controversial, says Morrison. For example, the US used an immunization effort in the hunt for Osama Bin Laden in Pakistan in 2011. The US "must do more to segregate its efforts to prevent, detect and respond to future outbreaks from counter-terror approaches," he argues. "There's always been a hesitation about health security policies. But I think that's changing. It's becoming a more constructive dialogue."

Morrison notes that the US military operates an international network of laboratories and health surveillance and research facilities in Cambodia, Egypt, Georgia, Germany, Kenya, Peru and Thailand that are well-suited to serving the GHSA's plan to establish emergency disease operations centres in India, Kenya, Ethiopia, Tanzania and six other as-yet-unnamed nations.

Canada will also contribute funding from security resources to the GHSA, according to Jean-Bruno Villeneuve, a spokesperson for Foreign Affairs, Trade and Development Canada. "The GHSA is intended to bring together a cross-sectoral representation of health, defense, foreign affairs and agriculture ministries from participating countries," he stated in an email. The Public Health Agency of Canada is also "closely following GHSA developments," according to Villeneuve.

Canadian support for the effort will come in part from the Global Partnership Program, which earmarked \$367 million in 2012 for the Global Partnership Against the Spread of Weapons and Materials of Mass Destruction.

The escalation of infectious diseases to national security threat status suggests a new global health paradigm may be emerging. According to the World Economic Forum's 2014 Global Risk Report, antibiotic resistance is a risk roughly on par with terrorist attacks.

A report issued by The CDC last year stated that antibiotic resistance was a complex problem and inaction could have "potentially catastrophic consequences." - Paul Christopher Webster, Toronto, Ont.

CMAJ 2014. DOI:10.1503/cmaj.109-4780 